\title{
Repetition Priming for Familiar and Unfamiliar Faces in a Sex-Judgment Task: Evidence for a Common Route for the Processing of Sex and Identity
}

\author{
Yonatan Goshen-Gottstein and Tzvi Ganel \\ Tel-Aviv University
}

\begin{abstract}
Repetition priming for faces was examined in a sex-judgment task given at test. Priming was found for edited, hair-removed photos of unfamiliar and familiar faces after a single presentation at study. Priming was also observed for the edited photos when study and test faces were different exemplars. Priming was not observed, however, when sex judgments were made at test to photos of complete, hair-included faces. These findings were interpreted by assuming that, for edited faces, internal features are attended, thereby activating face-recognition units that support performance. With complete faces, however, participants provided speeded judgments based primarily on the hairstyle. It is suggested that, for both familiar and unfamiliar faces, a common locus exists for the processing of the identity of a face and its sex. A single face-recognition model for the processing of familiar and unfamiliar faces is advocated.
\end{abstract}

In this article, themes from the implicit-memory literature were imported to improve our understanding of the processes involved in face recognition. Standard face-recognition models suggest that a benefit from prior exposure of the face should be observed only when information about the identity of the face is extracted (e.g., "Is the face that of a famous person?", "Is the face that of an actor?"). In contrast, we suggest that the extraction of visual facial information (e.g., the sex or emotion of the face) should also benefit from such prior exposure. Nonetheless, on the basis of notions developed in the implicit-memory literature, we argue that the extraction and retrieval of visual facial information can benefit from prior exposure of the face only if the stimulus is processed in its entirety, but not if processing neglects the perceptual whole. The respective predictions from the two literatures will be put to an empirical test.

On implicit-memory tests, memory is indexed by facilitation in performance that results from prior experience. To illustrate, in the speeded familiarity task, participants are presented during study with a series of familiar faces (e.g., a photo of Bill Clinton). Then, during test, they are presented with a second series that includes both studied and unstudied familiar and unfamiliar faces. Typically, participants decide that a face is familiar more accurately and more quickly if that face was previously shown in the first series (cf. Bruce \& Valentine, 1985; A. W. Ellis, Flude, Young, \& Burton, 1996). This facilitation in performance to studied as com-

Yonatan Goshen-Gottstein and Tzvi Ganel, Department of Psychology, Tel-Aviv University, Ramat Aviv, Israel.

Portions of this article were part of Tzvi Ganel's doctoral dissertation. We thank Vicki Bruce, Mike Burton, Robert E. Lubow, Dafna Bergertest, and Yoav Aryeh for their comments on earlier drafts of this article. We also thank Sagit Ganel for help with the graphic design of the stimuli.

Correspondence conceming this article should be addressed to Yonatan Goshen-Gottstein, Department of Psychology, Tel-Aviv University, Ramat Aviv 69978 Israel. Electronic mail may be sent to goshen@freud.tau.ac.il. pared with unstudied items is referred to as the repetition priming effect (e.g., Schacter, 1987).

Repetition priming has been demonstrated over a wide range of stimuli, including words (e.g., Jacoby \& Dallas, 1981), pronounceable nonwords (e.g., Bowers, 1994; Dorfman, 1994), word pairs (e.g., Goshen-Gottstein \& Moscovitch, 1995a, 1995b; Graf \& Schacter, 1985; Reingold \& Goshen-Gottstein, 1996), and line drawings (e.g., Schacter, Cooper, \& Delaney, 1990). Consistent repetition priming has also been demonstrated for familiar faces (for a review, see Bruce, Burton, Carson, Hanna, \& Mason, 1994), using speeded familiarity judgments (e.g., Bruce \& Valentine, 1985; A. W. Ellis, Young, \& Flude, 1990) or speeded naming (e.g., A. W. Ellis et al., 1990).

According to the memory-systems account (Moscovitch \& Umilta, 1990, 1991; Tulving \& Schacter, 1990), whenever a stimulus undergoes perceptual analysis, a perceptual record (Kirsner \& Dunn, 1985) is stored in domain-specific perceptual representation systems (for a description of candidate systems, see Schacter \& Tulving, 1994). The perceptual record contains presemantic structural information, whose reactivation, upon repeated presentation of the stimulus, results in facilitated processing. Therefore, facilitated processing of the stimulus reflects the greater ease with which the task-relevant recognition system can perceptually analyze the stimulus.

The memory-systems framework predicts that repeated presentation should facilitate performance whenever perceptual information is used in completing the task. This prediction is uniform for all classes of stimuli. Therefore, repetition priming should be found for unfamiliar faces, which participants have not encountered before, as well as for familiar ones. We now present a brief review, describing the surprising absence of repetition priming to unfamiliar faces. Two solutions are then outlined for the apparent puzzle raised by these null effects. One solution is advanced from face-recognition models (the parallel-route hypothesis) and the other from implicit-memory research (the truncated-processing hypothesis). 


\section{Absence of Repetition Priming to Unfamiliar Faces}

The decay function of repetition priming is much more rapid for unfamiliar faces (e.g., Bentin \& Moscovitch, 1988) than for other classes of stimuli (e.g., Goshen-Gottstein \& Kempinsky, in press), including familiar faces (Begleiter, Porjesz, \& Wang, 1994; Bentin \& McCarthy, 1994; Bentin \& Moscovitch, 1988; Roberts \& Bruce, 1989; Schweinberger, Pfutze, \& Sommer, 1995; for a possible exception, see Paller et al., 1992). Familiar-face repetition priming is maintained when many items are interleaved between an item's first and second presentation. These effects have been shown to persist for prime-target intervals lasting at least as long as one week (e.g., Bruce et al., 1994). In contrast, repetition priming for unfamiliar faces have either not been found at all (e.g., Campbell \& De Haan, 1998; Ellis et al., 1990) or have been found only when time intervals of a few seconds lapse between successive presentations and when no intervening items are displayed between first and second presentations (Bentin \& Moscovitch, 1988).

Because of their short-lived nature, these immediate-repetition priming effects for unfamiliar faces are uninformative with regard to how the face was initially processed. The benefit incurred by immediate repetition can be explained by the nearly perfect memory for the decision (e.g., face vs. nonface) that had just been made on the previous trial. The absence of long-lasting repetition priming to unfamiliar faces provides, therefore, an empirical puzzle.

One possible solution to the puzzle may be that unfamiliar faces constitute a unique class of stimuli for which the corresponding recognition system does not store a perceptual record. Indeed, evidence from different research paradigms suggests that familiar and unfamiliar faces are probably processed by different recognition systems. Thus, a double dissociation has been observed in prosopagnosic patients between recognition of familiar and unfamiliar faces (e.g., Carlesimo \& Caltagirone, 1995; Malone, Morris, Kay, \& Levin, 1982; Takahashi, Kawamura, Hirayama, Shiota, \& Isono, 1995; see also Warrington \& James, 1967). A recent positron-emission tomography (PET) study also supports this conclusion, with the activation of different brain regions upon presentation of familiar and unfamiliar faces (Andreasen et al., 1996). Also, dissimilar patterns of eye movements have been found in prosopagnosic patients when scanning familiar and unfamiliar faces (Rizzo, Hurtig, \& Damasio, 1987). Finally, recent studies have suggested that the pattern of evoked potentials may be different for the processing of familiar and unfamiliar faces (e.g., Uhl, Lang, Spieth, \& Deecke, 1990).

If familiar and unfamiliar faces are processed by different recognition systems, then their respective systems may be endowed with different processing capabilities. Still, this solution should not be embraced before less radical alternatives have been exhausted. Two such alternatives are now considered.

\section{The Parallel-Route Hypothesis}

The first solution is based on the notion that the tasks that have typically been used to probe memory for familiar faces have tapped different kinds of information, and hence used different functional (and neuro-anatomical) pathways, than those used for probing memory of unfamiliar faces. Familiar-face tasks have typically required using information regarding the identity (name, occupation, or other semantic information) of the depicted face, whereas unfamiliar-face tasks, by virtue of being unfamiliar, have not required retrieving identity information. Instead, when presented with unfamiliar faces, participants have typically been asked to perform face-physicality tasks, including answering questions regarding the integrity of the face (e.g., deciding whether a stimulus constitutes a face; Bentin \& Moscovitch, 1988), the sounds that are conveyed by the lip shape (i.e., Is the face on the screen saying "oo" or "ee"?; Campbell \& De Haan, 1998), the expression on the face (A. W. Ellis et al., 1990, Experiment 2), or the sex of the face (A. W. Ellis et al., 1990, Experiment 3).

According to face-recognition models (e.g., Bruce \& Young, 1986; Burton, Bruce, \& Johnston, 1990; Hay \& Young, 1982), information regarding the identity of individual faces is represented by view-independent abstract structural descriptions that are stored in face-recognition units (FRUs). These representations allow the identification of known faces. Face-recognition models suggest that repetition priming is produced by the reactivation of the representations that are stored in the FRUs (Bruce \& Young, 1986) or, alternatively, by the strengthening of connections between the FRUs and person identification nodes (PINs), where modality-independent information regarding the person, rather than the face, is represented (Burton et al., 1990). Critically, these models argue that when identity is not accessed, processing proceeds via routes that run parallel to the FRUs. Thus, according to this parallel-route hypothesis, face-physicality tasks are not mediated by FRUs and should not, therefore, produce repetition priming.

The idea behind the parallel-route hypothesis is quite profound in that it distinguishes between information regarding the identity of individual faces per se and information that is "similar to all 'facial action patterns' irrespective of the faces that are making them" (Bruce, 1988, p. 32). This hypothesis suggests that the human mind is equipped with specialized processing systems that are devoted to face-physicality tasks and that these specialized systems are different from the system involved in identifying a particular face.

What is the empirical evidence for the parallel-route hypothesis for face identity and visual information? First, a neuropsychological double dissociation exists between the processing of the identity of faces and the processing of the visual information contained in faces. Several studies describe patients who cannot recognize once-familiar faces, yet are able to make accurate judgments regarding expression and sex (Humphreys, Donnelly, \& Riddoch, 1993; Schweich \& Bruyer, 1993; Tranel, Damasio, \& Damasio, 1988; Young, Newcombe, De Haan, Small, \& Hay, 1993), alongside other patients who can identify faces but have difficulty in interpreting their expressions (e.g., Kurucz \& Feldmar, 1979). Second, blood-flow studies indicate activation of different brain areas when participants categorize faces according to their apparent sex compared with when they recognize familiar faces (Andreasen et al., 1996). Third, using neurologically intact participants, A. W. Ellis et al. (1990) asked participants to make expression judgments ("Is the face happy or sad?", Experiment 2) and sex judgments ("Is the face that of a man or of a woman?", Experiment 3) to faces. In both tasks, reaction times were not influenced by whether the faces being judged were familiar or not (see also Bruce, Ellis, Gibling, \& Young, 1987; Campbell, Brooks, De Haan, \& Roberts, 1996; Young, McWeeny, Hay, \& Ellis, 1986; but see Bruce, 1986). Judgments regarding visual characteristics of 
faces were, therefore, not influenced by the familiarity of the face. Finally, repetition priming was not obtained when the sexjudgment or the expression-judgment tasks were used. The analysis of faces as familiar seems, therefore, to be independent of the analysis of facial expressions and of apparent sex.

If the parallel-route hypothesis is correct, then FRUs, which are the locus of repetition priming effects cannot perform facephysicality tasks. This hypothesis is indifferent to the familiarityof-face and should be equally true for familiar, as it is for unfamiliar, faces. According to this hypothesis, therefore, the existence of repetition priming to familiar faces in conjunction with null effects to unfamiliar faces is an experimental artifact, because of a confound of familiarly-of-face (familiar, unfamiliar) with the implicit task that is used (identity task, face-physicality task)

Two predictions that will both be tested in this article can be derived from this hypothesis. First, because implicit memory requires measuring performance on a stimulus-relevant task, repetition priming should never be observable for unfamiliar faces in facial-expression or sex-judgment tasks (unless covert measures are used; see Alhoff \& Cohen, 1999). This prediction has never been articulated, yet it evolves directly from the hypothesis. Second, even for familiar faces, repetition priming should not be found if face-physicality tasks are used. Indeed, A. W. Ellis et al. (1990, Experiment 3) asked participants to judge either the sex or the apparent emotion of both familiar and unfamiliar faces and found repetition priming for neither stimulus class. According to the first solution, therefore, when the implicit task requires facephysicality judgments, repeated presentations of familiar, as well as unfamiliar, faces does not facilitate performance.

\section{The Truncated-Processing Hypothesis}

According to the second solution, the absence of repetition priming to faces in face-physicality tasks is not because information regarding physical aspects of the face is retrieved in parallel routes to the FRUs. To the contrary, FRUs can support different types of face-physicality information. This information, however, cannot be used if it was never adequately processed.

According to this solution, the processing of faces during facephysicality tasks may be inadequate for the formation of facial representations that subserve subsequent repetition priming. Considerable efforts have been expended to uncover constraining conditions under which repetition priming cannot emerge (e.g., Schacter, Cooper, Delaney, Peterson, \& Tharan, 1991). One such constraint may be that stimuli must be processed in their entirety, for repetition effects to emerge. Perhaps, face-physicality tasks inadvertently direct participants' attention away from the perceptual whole. This idea has been labeled by Roediger and McDermott (1993) as the "truncated-processing hypothesis."

This hypothesis has been invoked to explain, among other things, why the levels-of-processing manipulation affects the magnitude of repetition priming only in between-subjects designs. Thapar and Greene (1994; see also Challis \& Brodbeck, 1992) suggested that in the perceptual encoding conditions of betweensubjects designs, participants set themselves to restrict perceptual processings by, for example, only checking for g's. Because the rest of the word would not undergo perceptual analysis, this would reduce performance under perceptual encoding relative to semantic encoding. Such a strategy would be less practical in a within- subject design, where processing tasks vary in an unpredictable manner (see also Hayman \& Jacoby, 1989). Thus, the benefit of prior exposure may be much reduced if participants do not perceptually analyze the whole stimulus.

A related explanation may be used to account for the absence of repetition priming in face-physicality tasks. If participants performing these tasks adopt heuristics that allow them to make accurate judgments in the easiest, quickest way, then they may use only part of the perceptual information made available to them, thereby neglecting, or truncating, the perceptual whole. Arguably, such heuristics may prevent repetition priming from emerging for both familiar and unfamiliar faces.

In the studies reported in this article, we chose to explore this explanation using the sex-judgment task. This task was chosen because the heuristic that we believed mediates performance on this task could be overcome by experimental manipulations. We suggest that in judging the apparent sex of faces, participants apply a hair heuristic, whereby judgments are made by focusing attention on the hairstyle while ignoring the internal facial features. Because internal facial features are not processed, the minimal conditions for obtaining repetition priming are not satisfied and the effects cannot emerge. To restrain participants from applying this postulated heuristic, we will delete the hair from our facial stimuli. This should force participants to analyze the perceptual whole and process the crucial internal facial features.

In the experiments described here, the predictions of the parallel-route hypothesis and the truncated-processing hypothesis are pitted against each other by presenting faces for sex judgments either with hair (i.e., complete faces) or without hair (i.e., edited faces). To anticipate the results, we observed repetition priming for both unfamiliar and familiar faces when edited faces were presented for sex judgments, but not when complete faces were presented. This implicates the role of FRUs in sex judgments by demonstrating that when the internal facial features are processed, repetition priming can emerge.

Because a common method was used throughout most of the article, we first describe the General Method for the experiments that investigated unfamiliar faces (pilot experiment, Experiments 1, 2, \& 3). Subsequently, within each experiment, we describe deviations from the General Method.

\section{General Method}

\section{Participants}

Participants with normal or corrected-to-normal vision either received course credit or were paid $\$ 4$. None participated in more than one experiment.

\section{Design and Materials}

In all of the experiments, study status (studied, unstudied) and sex-offace (male, female) were manipulated within subject. Between-subjects variables were only manipulated in some experiments and will be described when relevant.

The stimuli consisted of 28 male and 28 female unfamiliar faces downloaded from various Internet sites. Male faces did not contain facial hair, and all photos depicted faces that bore neither jewelry nor any other paraphemalia that could help predict face sex (e.g., glasses). Care was taken to choose faces with neutral expressions. See Figure 1 for sample stimuli. 


\section{Complete Faces}
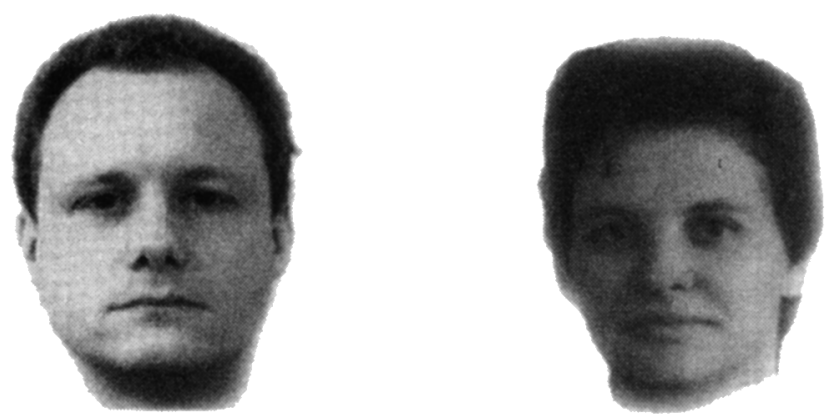

\section{Hair and Overall Structure Only}
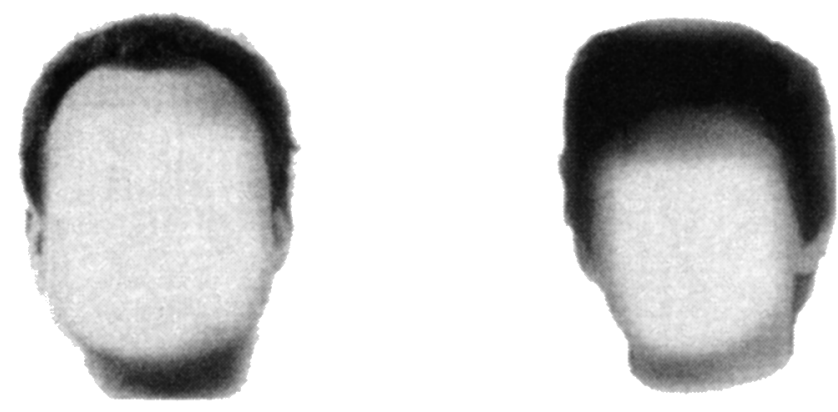

\section{Edited Faces}
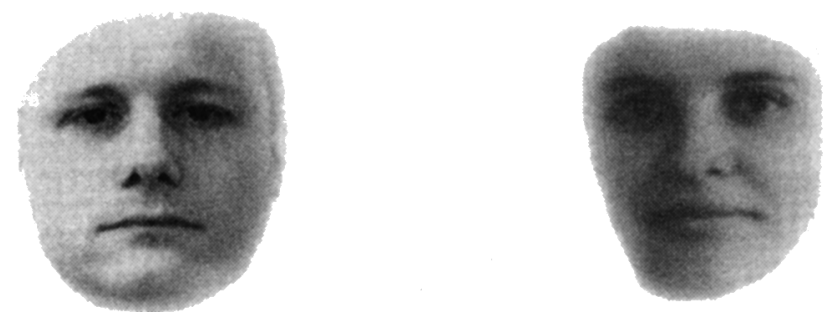

Figure 1. Sample photos of unfamiliar faces presented in the pilot experiment (hair only) and in Experiments 1,2, and 3 (complete and edited faces).

Using the Adobe PhotoShop 5.0 software package, all of the photos were equated in size so that they were $7.5 \mathrm{~cm}$ long and $5.3 \mathrm{~cm}$ wide. Furthermore, the contrast between the face and the background, subjectively determined by the experimenter, was kept constant. The color of the background was set to white. We refer to the resultant photos as the stimulus set.

The stimulus set was randomly divided into two equal groups of photos, so that each group contained an equal number of male and female faces. For each participant, one group was presented during the study phase, and both groups were presented during the test phase. Thus, each participant was presented during test with an equal number of studied and unstudied faces and an equal number of male and female faces. Across participants, each face was presented an equal number of times in the studied and unstudied conditions.

\section{Procedure}

During study, individually tested participants were told that they would be shown photographs of faces and asked to rate their apparent intelligence.
This task was chosen because it has been found to produce excellent (explicit) memory performance (e.g., Bower \& Karlin, 1974; Patterson \& Baddeley, 1977; Winograd, 1976). At no time during the experiment was reference made to the fact that memory was being investigated.

Three practice trials, in which feedback was given, were first administered. Next, the study stimuli were presented on the screen of a Macintosh Power PC computer in random order for each participant. Each stimulus was presented for $5 \mathrm{~s}$, after which it disappeared. Intelligence ratings were to be made immediately after each photo disappeared. Judgments that a face was of low intelligence were to be registered by pressing the 3 key on the number keypad with the right-hand index finger; a high-intelligence judgment was to be made by a $l$ response with the left-hand index finger (orders were reversed, in all experiments, for left-handed participants). Participants' keypress responses immediately activated the next trial.

For test, participants were told that they would see a series of faces and that they were to decide, as quickly as possible with the least errors, if the photo depicted a man (dominant hand, 3) or a woman (nondominant hand, l). Six practice trials, which included the photos of three men and three women in which feedback was given, were then administered. Subsequently, the test series was administered, in a different random order for each participant.

Each test trial began with a waming signal (an asterisk) that was presented for $1 \mathrm{~s}$. immediately followed by a face stimulus. The stimulus remained on the screen until a response was recorded, at which point the stimulus disappeared. The next trial began $2 \mathrm{~s}$ after a participant's response. The time interval between a face being seen in the study phase and again in the test phase varied from 3 to $11 \mathrm{~min}$. The number of stimuli interleaved between the first and second presentation of a face varied from a minimum of 6 to a maximum of 89 items.

\section{Pilot Experiment}

The purpose of the pilot experiment was to examine whether the information that is available in hairstyle and overall face structure is sufficient to make accurate sex judgments. Because hair styles are typically sex specific, the information contained within them may guide sex judgments on speeded tasks. Only if accurate sex judgments can be made on the basis of such information is it conceivable that participants neglect internal facial features and rely on hairstyle information when asked to make sex judgments. Therefore, we deleted internal facial features and facial texture from the set of unfamiliar faces. Could accurate sex-judgment performance be obtained when facial stimuli contained only hairstyle and overall face structure?

\section{Method}

A total of 18 Tel-Aviv undergraduates, 13 of them women, participated in the experiment. Using the Adobe PhotoShop 5.0 software package, all internal facial features and facial texture were deleted from the unfamiliar faces of the stimulus set. See Figure 1 for sample hairstyle stimuli.

During study, participants made intelligence judgments to complete faces that included internal facial features. During test, participants were forewarned that a series of faces that contained no internal facial features and no texture would be presented. They were asked to make speeded sex judgments to these faces. In all other respects, the method conformed to the general method.

\section{Results and Discussion}

Participants were remarkably accurate in their sex judgments, making correct judgments to $88.9 \%(S E=0.014)$ of studied faces and to $89.1 \%(S E=0.014)$ of unstudied faces. This difference was 
not significant, $t(17)=0.09$. Means were also calculated from the reaction time (RT) distributions of correct responses whose skewness was removed by eliminating ( $2.6 \%$ of) responses that were slower than $3.5 \mathrm{~s}$. Examination of the data revealed that mean response times to unstudied faces $(961 \mathrm{~ms} ; S E=69)$ were not significantly different from responses to studied faces $(981 \mathrm{~ms}$; $S E=60), t(17)=0.30$.

The purpose of this experiment was to examine whether a heuristic that helps judge sex by the information available in hairstyle and overall face structure could support accurate performance. Given the impoverished, informationally poor stimuli, we found participants' performance to be exceptionally good. As a comparison, Burton, Bruce, and Dench (1993) examined which internal facial features enable humans to categorize faces according to sex. In their study, internal facial features were displayed, and only the hair was deleted from photographs. Although participants were allowed to make slow, deliberate judgments to the informationally rich stimuli, they were only $7 \%$ more accurate than participants in the present experiment. (For descriptions of the processes involved in slow, deliberate sex judgments, see Bruce et al., 1993; Bruce \& Langton, 1994; O'Toole et al., 1997).

In conclusion, if the consequences of making a wrong judgment are not devastating, as in an artificial, laboratory-based sexjudgment task, participants' sex judgments could, at least in part, rely on nonfacial aspects of photographed stimuli.

\section{Experiment 1}

In Experiment 1, edited photos were created by deleting the hair from the unfamiliar faces of our stimulus set. According to the parallel-route hypothesis, repetition priming was predicted to not emerge, because judgments regarding sex do not involve FRUs. According to truncated-processing hypothesis, however, participants' attention would be drawn, during the sex-judgment task, to internal facial features of hair-deleted faces, leading to an analysis of the faces in their entirety. FRUs would then be activated, and repetition priming should consequently emerge.

We also examined the effects that study format (complete, edited) might have on the emergence of repetition priming effects. Under the guise of the encoding-specificity principle (Tulving \& Thompson, 1973), explicit memory research has demonstrated, that, in general, memory performance is enhanced to the extent that study and test conditions resemble each other. We, therefore, explored to what extent performance in our study would also be affected by changing format-of-presentation from study (complete faces) to test (edited faces). Thus, one half of the participants were presented with edited faces during study and one half with complete faces.

\section{Method}

In all, 64 Tel-Aviv undergraduates, 44 women, participated in the experiment. During study, one half of the participants were presented with edited, hair-deleted faces and one half with complete faces for an intelligence-rating task. During test, only edited faces were presented for the sex-judgment task. Participants were randomly allocated to the two study-format (edited, complete) conditions, with the constraint that the proportion of male to female participants was equal in the two conditions.

Stimuli for the edited-face condition were created by deleting all the hair and contours from the complete stimulus set of unfamiliar faces, using the
Adobe PhotoShop 5.0 software package. Only the internal facial features and the facial texture remained. The size of each photo was $5.3 \mathrm{~cm}$ in length and $4.3 \mathrm{~cm}$ in width. The edited faces were complements of the pilot-experiment stimuli, in that combining the photographs from the two experiments would produce the complete faces of the stimulus set. See Figure 1 for sample stimuli.

\section{Results}

For each participant, mean RTs (expressed in ms) were calculated from the distribution of correct responses, whose skewness was reduced by eliminating outliers slower than $3.5 \mathrm{~s}$. Fewer than $2 \%$ of responses were eliminated for this reason. These means were then averaged across the 32 participants in the two betweensubjects conditions. Table 1 displays the means of the by-subject ${ }^{1}$ analysis, and Table 2 displays the mean percentage of errors.

The data were submitted to an analysis of variance (ANOVA), with study status (studied, unstudied) and sex-of-face (male, female) as within-subject variables and study format (edited, complete) as a between-subjects variable. For this, and subsequent analyses, only effects achieving significance at the $\alpha=.05$ level are reported. Unless otherwise noted, all hypotheses were treated as two-tailed.

Mean RTs were $90 \mathrm{~ms}$ faster after the edited-face study condition than the complete-face study condition, by subjects, $F_{1}(1$, $62)=4.84, M S E=106,517$, and by items, $F_{2}(1,110)=14.32$, $M S E=35,956$. Also, RTs to male faces were $88 \mathrm{~ms}$ faster than to female faces, $F_{1}(1,62)=29.14, M S E=16,944$. Most important, repetition priming was observed, with $\mathrm{RT}$ s to studied faces being $31 \mathrm{~ms}$ faster than RTs to unstudied faces, $F_{1}(1,62)=6.15$, $M S E=9,997 ; F_{2}(1,110)=12.03, M S E=7,131$. No two-way or three-way interactions achieved significance, all $F_{\mathrm{S}}<1$.

Examination of the error data revealed a nonsignificant effect, $F(1,62)=2.46, M S E=57$, of $1.4 \%$ fewer errors made to faces in the edited-face study condition than in the complete-face study condition. The $5.8 \%$ male versus female face difference (fewer errors for male faces) was, however, significant, $F(1,62)=30.43$, $M S E=70$. Most important, significantly fewer $(1.2 \%$ fewer $)$ errors were made to studied faces than to unstudied faces, $F_{1}(1$,

I To validate our conclusions, we also analyzed all results by items (Clark, 1973). In the by-subject analysis $\left(F_{1}\right)$ sex-of-face was a withinsubject factor. In the by-item analysis $\left(F_{2}\right)$, however, sex-of-face was a between-subjects factor. Because the statistical power inherent to designs that include the two types of factors is variable, we did not include this factor in the analysis. Hence, only the main effects of study format (between subjects) and study status (within subject) are reported throughout the article. For each photo, means were calculated from RT distributions of correct responses, whose skewness was reduced by responses slower than $3.5 \mathrm{~s}$, for participants in the 2 (study status) $\times 2$ (study format) conditions. These means were then averaged across the 56 photos. Once outliers were removed, averaging in the by-subjects analysis and by-items analysis was across a different number of responses (32 participants vs. 56 photos, per between-subjects condition). Therefore, slightly different means were obtained in the two analyses. For sake of brevity, we report means only from the by-subjects analysis. 
Table 1

Experiments 1-5: Mean Reaction Times and Priming Effects (Unstudied-Studied) to Male and Female Faces Under the Two Study-Format Conditions

\begin{tabular}{llllllll}
\hline Study-format & \multicolumn{3}{c}{ Edited } & & \multicolumn{3}{c}{ Complete } \\
\cline { 2 - 3 } \cline { 5 - 6 } Sex-of-face & Male & Female & Overall & & Male & Female & Overall \\
\hline
\end{tabular}

Experiment 1 (unfamiliar faces; intelligence judgment at study; edited faces at test)

\begin{tabular}{lrrrrrr} 
Studied & 743 & 818 & 781 & 818 & 924 & 871 \\
Unstudied & 774 & 851 & 813 & 855 & 948 & 902 \\
Priming & 31 & 33 & 32 & 37 & 24 & 31 \\
\hline
\end{tabular}

Experiment 2 (unfamiliar faces; intelligence judgment at study; complete faces at test)

\begin{tabular}{lrrrrrr} 
Studied & 826 & 868 & 847 & 732 & 730 & 731 \\
Unstudied & 821 & 882 & 852 & 709 & 745 & 727 \\
Priming & -5 & 14 & 5 & -23 & 15 & -4 \\
\hline
\end{tabular}

Experiment 3 (unfamiliar faces; sex judgment at study; edited faces at test)

\begin{tabular}{|c|c|c|c|c|c|c|}
\hline Studied & - & 一 & 一 & 727 & 842 & 784 \\
\hline Unstudied & - & - & - & 741 & 833 & 787 \\
\hline Priming & - & - & - & 14 & -9 & 3 \\
\hline
\end{tabular}

Experiment 4 (familiar faces; intelligence judgment at study; edited and complete faces at test)

\begin{tabular}{lrrrrrr} 
Studied & 605 & 626 & 615 & 609 & 650 & 629 \\
Unstudied & 697 & 681 & 689 & 633 & 664 & 648 \\
Priming & 92 & 55 & 74 & 24 & 14 & 19 \\
\hline
\end{tabular}

Experiment 5 (familiar faces; exemplar shift; intelligence judgment at study; edited faces at test)

\begin{tabular}{|c|c|c|c|c|c|c|}
\hline Studied & 559 & 601 & 580 & - & - & - \\
\hline Unstudied & 584 & 626 & 605 & - & 一 & 一 \\
\hline Priming & 25 & 25 & 25 & - & - & - \\
\hline
\end{tabular}

Note. In all experiments, sex judgments were made at test.

62) $=3.725, M S E=25$, one-tailed, ${ }^{2}$ demonstrating repetition priming also in the accuracy data. Although the by-items analysis did not yield a significant study status effect, $F_{2}(1,111)=1.31$, $M S E=0.006, p>.05$, numerically better performance was observed for studied faces. This, together with the significant by-subjects effect, indicated that the repetition priming observed in the latency data could not be accounted for by a possible speed accuracy trade-off. All interactions failed to achieve significance, all $F \mathbf{s}<1$.

\section{Discussion}

The most important finding in Experiment 1 was that responses were both faster and more accurate to studied than to unstudied faces. This provided the first documented demonstration of repetition priming for once-presented faces at long lags and over study-test durations that last longer than a few seconds. We propose that by presenting hair-deleted faces for sex judgments, participants' attention was directed at processing the internal facial features. Processing these features activated FRUs that had been created at study and this facilitated subsequent performance.

An unexpected result was the sex-of-face effect, with faster and more accurate processing of male faces than of female faces. One interpretation of this result may be that the facilitated processing observed for male faces was confounded with responses made by the dominant hand. However, an independent replication of this study, with sex judgments made with the reverse order of hands, still found $66 \mathrm{~ms}$ faster RTs to male faces than to female faces, $F(1,21)=7.02, M S E=11,826$. Also, $3.6 \%$ significantly more accurate responses were made to male faces than to female faces, $F(1,20)=3.56, M S E=0.01$, one-tailed. Dominance of hand could not be invoked, therefore, to dismiss the sex-of-face effect as artifactual.

Still, the sex-of-face effect may stem from a more subtle confound. Participants may have subjectively transformed the sexjudgment task into a "Is it a male?" task. For this task, positive responses, which are invariably faster than negative responses, would be given only to photos depicting men, thereby explaining the superior processing found for these photos (see Wentura, 2000, for a similar analysis in a different domain).

In addition, the sex-of-face effect may also be driven by the larger disfigurement that is caused, by the removal of hair, to faces of women than to faces of men. Because it is not uncommon, at least in Western society, to perceive male heads without hair, removal of hair disfigures female faces to a greater extent than male faces (also see Bruce et al., 1991). Reduced exposure to hairless female faces may account for the slower processing of these faces.

\footnotetext{
${ }^{2}$ When $F$ has $1 d f$ in the numerator, then $F=t^{2}$. A one-tailed test can, therefore, be reported.
} 
Table 2

Experiments 1-5: Mean Percentage Errors and Priming Effects (Unstudied-Studied) to Male and Female Faces Under the Two Study-Format Conditions

\begin{tabular}{llllllll}
\hline Study format & \multicolumn{3}{c}{ Edited } & & \multicolumn{3}{c}{ Complete } \\
\cline { 2 - 3 } \cline { 6 - 7 } Sex-of-face & Male & Female & Overall & & Male & Female & Overall
\end{tabular}

Experiment 1 (unfamiliar faces; intelligence judgment at study; edited faces at test)

\begin{tabular}{lcccccr} 
Studied & 1.4 & 6.7 & 4 & 1.3 & 7.8 & 4.6 \\
Unstudied & 2.8 & 5.8 & 4.3 & 2.6 & 10.8 & 6.7 \\
Priming & 1.4 & -0.9 & 0.3 & 1.3 & 3 & 2.1 \\
\hline \multicolumn{7}{r}{} \\
Studied & Experiment 2 (unfamiliar & faces; intelligence & judgment at study; complete & faces at test) \\
Unstudied & 1.8 & 1.6 & 1.7 & 3.1 & 3.1 & 3.1 \\
Priming & 0.9 & 1.6 & 1.25 & 2 & 2.4 & 2.2 \\
\hline
\end{tabular}

Experiment 3 (unfamiliar faces; sex judgment at study; edited faces at test)

\begin{tabular}{lllllrl} 
Studied & - & - & - & 1 & 13 & 7 \\
Unstudied & - & - & - & 1 & 14 & 7.5 \\
Priming & - & - & - & 0 & 1 & 0.5 \\
\hline
\end{tabular}

Experiment 4 (familiar faces; intelligence judgment at study; edited and complete faces at test)

\begin{tabular}{lrlllll} 
Studied & 2.6 & 3 & 2.8 & 0.4 & 1.5 & 0.9 \\
Unstudied & 2.2 & 4.1 & 3.1 & 1.1 & 3.7 & 2.4 \\
Priming & -0.4 & 1.1 & 0.3 & 0.7 & 2.2 & 1.5 \\
\hline
\end{tabular}

Experiment 5 (familiar faces; exemplar shift; intelligence judgment at study; edited faces at test)

\begin{tabular}{|c|c|c|c|c|c|c|}
\hline Studied & 1.5 & 4.1 & 2.8 & - & - & - \\
\hline Unstudied & 2.2 & 4.8 & 3.5 & - & - & - \\
\hline Priming & 0.7 & 0.7 & 0.7 & - & - & - \\
\hline
\end{tabular}

Note. In all experiments, sex judgments are made at test.

The study-format effect describes the finding that faces that had been studied as edited were processed faster than faces that had been studied as complete. Faces studied as edited did not undergo a shift in format between study and test. For faces studied as complete, however, a shift in format occurred between study (complete) and test (edited). This change in format probably resulted in additional processing of test faces, leading to slower response times.

To confirm this interpretation, we analyzed the unstudied faces alone, to see if the change in format showed a similar pattern to faces that had never been seen before. Unstudied faces that were presented during test with faces that had been presented in the complete-face study condition, were processed 89 ms slower than unstudied faces that were presented during test with faces that had been presented in the edited-face study condition. This difference was significant, $F_{1}(1,62)=3.77, M S E=36,233 ; F_{2}(1$, $110)=10.32, M S E=25,722$. Because unstudied faces showed slower processing when they appeared with studied faces for which the format was shifted, an overall processing strategy must be implicated that affected studied faces in the same way as it affected unstudied faces.

Note that whereas overall processing was affected by format compatibility between study and test, repetition priming was unaffected by this variable. Repetition priming in the same-format condition was $32 \mathrm{~ms}$ and was equivalent to the $31-\mathrm{ms}$ effect in the different-format condition. This finding is important for determining the nature of the representation mediating the effect. Had the effect been mediated by a view-dependent pictorial code, then it should have been attenuated when format was switched between study and test. That repetition priming was unchanged, suggests that the effect was mediated by an abstract, view-independent representation. More direct evidence for this idea will be provided in Experiment 5.

\section{Experiment 2}

In Experiment 1, we demonstrated that repetition priming could be observed for unfamiliar faces using a sex-judgment task for faces for which the hair was deleted. A. W. Ellis et al. (1990) failed to find such effects for complete faces. We argued that the critical factor responsible for this difference was whether the facial stimuli included hair (A. W. Ellis et al., 1990) or did not include hair (Experiment 1).

However, alternative interpretations remain open. A combination of factors may have worked together to produce the different results in the two studies. First, different stimuli were used in the two studies and may have been responsible for the contradictory results. Second, in the A. W. Ellis et al. (1990) study, face photos were not standardized in size or perceived brightness, possibly elevating overall variability. Third, in the A. W. Ellis et al. (1990) study, a warning signal was not presented during test trials prior to stimulus presentation, thereby increasing the variability of response times. Fourth, results were not corrected for outliers, again increasing variability. Finally, in each experimental condition, 
only a small sample ( $n=12$ ) was tested. Together with the (relatively) small number of responses collected in each condition (16), their design may have lacked sufficient statistical power to detect the effects of repetition.

To rule out these factors as responsible for the different results across the two studies, we used hair-included versions of the Experiment-1 stimuli. We predicted that participants would use a hair heuristic, thereby ignoring the internal facial features. Repetition priming was predicted, therefore, to not emerge.

\section{Method}

A total of 64 Tel-Aviv undergraduates, 44 women, participated in the experiment. The method was identical to that used in Experiment 1, except that during test, participants were presented with hair-included faces.

\section{Results and Discussion}

Corrected mean RTs were calculated as in Experiment 1, and are represented in Tables 1 and 2 along with the mean percentage of errors. Examination of the results revealed that RTs to male faces were $34 \mathrm{~ms}$ faster than to female faces, $F(1,62)=11.79$, $M S E=6,353$. In contrast to Experiment 1, mean RTs to faces in the edited-face study condition were $120 \mathrm{~ms}$ slower, not faster, than RTs in the complete-face study condition, $F_{1}(1,62)=4.75$, $M S E=194,688 ; F_{2}(1,110)=51.52, M S E=15,317$. Most important, no priming was observed with equal RTs to studied and to unstudied faces, $F_{1}(1,62)<1, M S E=10,669 ; F_{2}<1$, $M S E=13,722$. All interactions failed to achieve significance, all $F$ s $<1$.

Examination of the error data revealed that $1.2 \%$ fewer errors were made to faces in the edited-face study condition than in the complete-face study condition, $F(1,62)=4.15, M S E=23$. Therefore, the faster processing that was observed for faces that had been studied as complete may have been the result of a speed-accuracy trade-off strategy. The $0.25 \%$ fewer errors made to male faces than to female faces was not a significant difference, $F(1,62)<1, M S E=13$. Most important, a reverse pattern from the latency data was found with studied faces being processed $0.7 \%$ less accurately than unstudied faces. Still, this effect was not significant, $F(1,62)<1, M S E=14$. All interactions failed to achieve significance, all $F \mathrm{~s}<1$.

In neither latency performance nor accuracy performance was evidence found for repetition priming of unfamiliar faces. Therefore, we conclude that when complete faces are processed during test, repetition priming is not found.

\section{Analyses Across Experiments 1 and 2}

Because our arguments are based on findings across experiments, we further analyzed our results as collected from a single design. First, we compared overall RTs in Experiments 1 and 2. Mean RTs when sex judgments were made to edited faces were 52 ms slower than when made to complete faces, $F(1,126)=2.17$, $M S E=39,728, p=.07$, one-tailed. This confirms the notion that removal of the hair in Experiment 1, induced deeper, more demanding processing.

Next, we analyzed the entire data set with study format (edited, complete) and test format (edited, Experiment 1; complete, Experiment 2) as between-subjects variables, and sex-of-face (male, female) and study status (studied, unstudied) as within-subject variables. We corrected for the effects of counterbalancing, as recommended by Pollatsek and Well (1995). For sake of brevity, we do not report main effects when these enter into significant interactions.

We found a significant two-way interaction between test-format and study-status, $F_{1}(1,120)=4.8, M S E=8.457 ; F_{2}(1$, 220) $=4.28, M S E=10,452$. Thus, the $30-\mathrm{ms}$ repetition priming effect that was observed when edited faces were presented during test (Experiment 1) was significantly larger than the 0 -ms effect found in the complete-face test condition (Experiment 2). The two-way interaction between study format and study status, however, was not significant, nor was the three-way interaction between study format, test format, and study status, all $F \mathrm{~s}<1$.

In the accuracy data, the main effect of study status was not significant, $F_{1}(1,120)<1 ; F_{2}(1,220)<1$, indicating that across experiments, responses to studied faces were not more accurate than to unstudied faces. The observed interaction, however, told the more compelling story. The two-way interaction between test format and study status was significant, $F(1,120)=6.18$, $M S E=18$. Thus, the $1.2 \%$ priming effect that was observed when edited faces were presented during test (Experiment 1) was significantly larger than the $-0.7 \%$ effect in the complete-face test condition (Experiment 2). The interaction between study format and study status did not achieve significance, $F(1,120)=1.02$, $M S E=18$, and nor did the three-way interaction between study format, test format, and study status, $F(1,120)=2.3, M S E=18$.

Together, the presence of repetition priming in the sex-judgment task, in both the accuracy and the latency data, seems to be entirely predicted by the format of the photos during test, regardless of study format. As predicted by the truncated-processing hypothesis, we found that so long as edited faces are presented for sex judgments, repetition priming can emerge.

\section{Experiment 3}

In Experiment 3, we wanted to generalize the predictions made by the truncated-processing hypothesis to the study phase by presenting complete faces at study for a sex-judgment task. According to this hypothesis, a hair heuristic would be applied and the internal features would not be processed. Consequently, FRUs would not be created and repetition priming would be predicted not to emerge.

One study casts doubts on this prediction. Using familiar faces, A. W. Ellis et al. (1990) presented complete faces during both study and test. Participants made sex judgments during study and familiarity judgments during test. According to the truncatedprocessing hypothesis, the internal features should have been ignored because of the nature of sex-judgment processing. Therefore, FRUs should not have been activated, and repetition priming should not have appeared in the subsequent familiarity judgment task. Contrary to this prediction, repetition priming was found. Because these results contradict our prediction, we wished to further explore this issue by using our materials and task.

\section{Method}

Study status (studied, unstudied) was manipulated within subject. In this experiment alone, sex judgment, rather than intelligence rating, was used as 
the encoding task. A total of 18 participants were asked to make sex judgments to complete faces at study and edited faces at test.

\section{Results and Discussion}

Corrected mean RTs were calculated as in Experiment 1 and are reported in Tables 1 and 2 along with mean error rates. In agreement with the earlier experiments, a sex-of-face effect was found, with $103 \mathrm{~ms}$ faster responses to male than to female faces, $F(1$, $17)=32.6, M S E=5,889$, and $12 \%$ fewer errors to male than to female faces, $F(1,17)=25.4, M S E=0.01$. The interaction between study status and sex-of-face was significant neither by subject or by item analysis, both $F \mathrm{~s}<1$.

Most important, reaction times for studied faces were a nonsignificant $3 \mathrm{~ms}$ slower than for unstudied faces, $F_{1}(1,17)<1$, $M S E=5,805 ; F_{2}(1,55)<1, M S E=10,271$, and $1 \%$ less accurate, $F(1,17)<1, M S E=0.004$. It seems, therefore, that FRUs were not created when participants encoded faces by making sex judgments to complete faces. This strengthens the notion that upon making sex judgments to complete faces, participants ignore internal facial features.

The results of this experiment shed further light on the inability of A. W. Ellis et al. (1990) to observe repetition priming when participants were presented with complete faces during both study and test and made sex judgments at both times. According to the truncated-processing hypothesis, the failure of A. W. Ellis et al. (1990) to observe repetition priming can be attributed to two independent sources. First, as suggested by Experiment 2, hairincluded faces were presented during test, so participants ignored the internal facial features. Second, as suggested by this experiment, also during study, critical features may have been ignored because participants categorized hair-included faces by sex. Each of these sources alone may have been sufficient to block repetition priming effects.

The results of this experiment do not replicate the findings of A. W. Ellis et al. (1990, Experiment 3), who found repetition priming also in conditions in which participants studied complete faces using the sex-judgment task and made familiarity judgments at test. One difference between the design of the present study and that of A. W. Ellis et al. (1990) may possibly account for the discrepant results. A. W. Ellis et al. (1990) presented both familiar and unfamiliar faces during study, in a completely random (withinsubject) design. It may be that the inclusion of two classes of stimuli in their design directed more attention to the internal facial features, thereby overriding the heuristic that participants would have otherwise used. Indeed, evidence from several experimental paradigms (e.g., generation, Beg \& Snider, 1987; word frequency, Gregg, 1976; and presentation modality, Greene, 1989) suggests that variables that are intermixed within a design may often affect performance in ways that are different from their affects when they appear in segregated conditions. Therefore, in the Ellis et al. (1990) design, the application of the hair heuristic may have been less susceptible to strategic (or heuristic) processing. Research underway in our lab is currently investigating the possible effects of design on the emergence of repetition priming.

Either way, it seems that if FRUs are to be created, attention must be directed during study to internal facial features, so that these features can be extracted. That the intelligence-ratings task in Experiment 1 lead to subsequent repetition priming, therefore, suggests that this task must have used information that was available only in the entire face, and local heuristics were not applied. Accordingly, even at test, if this task was directed at complete faces, repetition priming should be found. This prediction awaits further experimentation.

The foregoing discussion highlights the difficulty in generalizing from our findings to other tasks. The conclusion that implicit memory for unfamiliar faces is unaffected by study format (edited, complete), and requires the presentation of edited faces at test, can be justified only for the particular combination of tasks reported in the prior experiments. For implicit memory to be observed on other task combinations, the stimuli may have to be edited in different, task-relevant ways to offset the operations of local heuristics. More on this in the General Discussion section.

\section{Experiment 4}

In Experiment 1, repetition priming was found for unfamiliar faces using the sex-judgment task. That judgments of sex can be made by FRUs casts doubts on the validity of the parallel-route hypothesis. Although the demonstration of repetition priming to unfamiliar faces is novel, the interpretation of this effect may still be contended.

It could be argued that FRUs do not mediate the effects, because FRUs are (as their acronym suggests) only able to recognize faces, but cannot perform sex judgments. If FRUs could perform sex judgments, the argument would go, then repetition priming effects should also be found for familiar faces, which they are not (A. W. Ellis et al., 1990). Hence, if the effects are to be interpreted as stemming from the reactivation of representation in the FRUs, rather than the reactivation of some other form of representation, then sex judgments must also produce repetition priming for familiar faces, which are known to be represented by FRUs.

In Experiment 4, familiar faces were presented at test for sex judgments in either their edited or their complete format. According to the parallel-route hypothesis, FRUs do not support sex judgments and repetition priming is predicted to emerge for neither complete nor edited faces. According to the truncated-processing account, however, once the internal facial features are processed, FRUs can make sex judgments. Therefore, repetition priming should emerge for the edited faces, but not for the complete faces.

\section{Method}

\section{Participants and Materials}

In all, 36 participants participated in Experiment 4. New facial stimuli were created, by digitizing, standardizing, and editing 30 male and 30 female photos of famous entertainers and politicians. See Figure 2 for sample stimuli.

\section{Design and Procedure}

Test format (edited, complete) was manipulated between subjects and, because study format (edited, complete) did not affect the magnitude of repetition priming in Experiments 1 and 2, was confounded with study format. Hence, one half of the faces were presented during both study and test as edited and one half as complete. This mimicked the conditions in Experiments 1 and 2 that lead to the best overall performance.

During study, participants were told that they would see faces that were familiar to them and were asked to judge how intelligent the person 

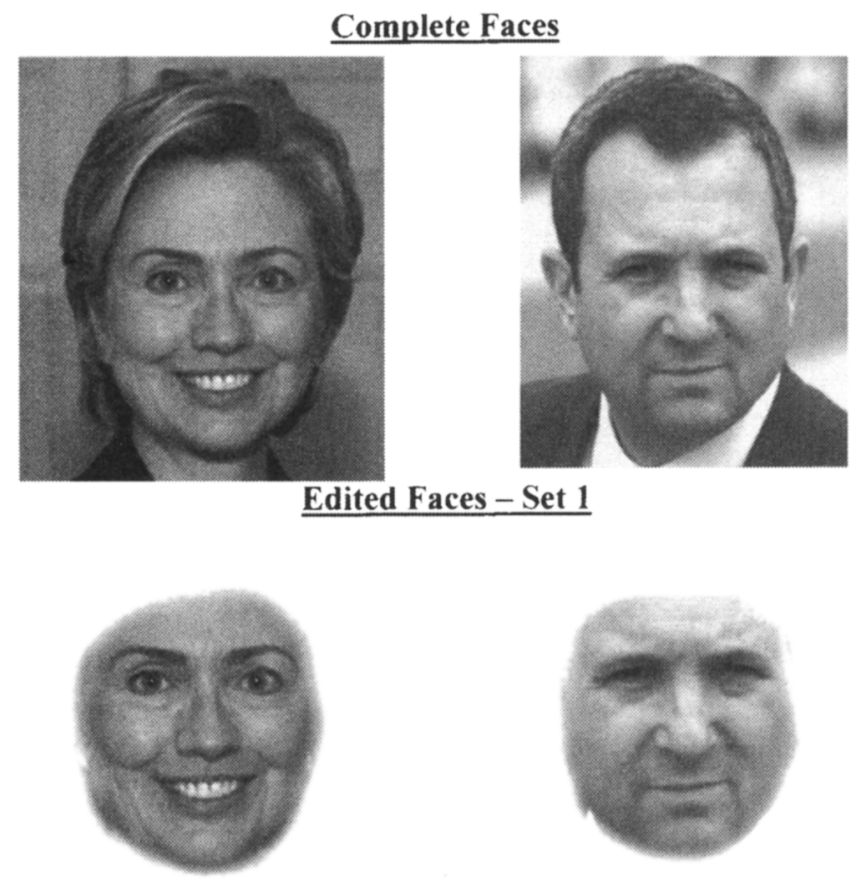

Edited Faces - Set 2

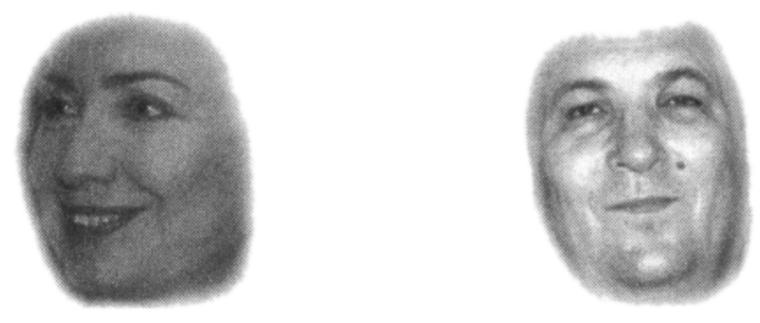

Figure 2. Sample photos of familiar faces presented in Experiment 4 (Set 1, complete and edited faces) and in Experiment 5 (Set 2, edited faces). Photos depict Hillary Clinton, First Lady; Ehud Barak, Israeli Prime Minister. Photographed by Sa'ar Ya'acov and Avi Ohayon. Copyright 1998 by the National Photo Collection of The State of Israel. Reprinted with permission.

appeared. To equate encoding strategies, participants were discouraged from making actual ratings of the person's intelligence. During test, participants made sex judgments.

To ensure that the faces were recognized, we showed participants the entire 60-face series at the end of the experiment. They were asked to provide biographical information (e.g., name or occupation) about each photo. Only photos for which correct information was provided were included in the analysis of that participant. In all other respects, the method was identical to that of Experiments 1 and 2.

\section{Results and Discussion}

Means were calculated only for those faces for which participants could provide some biographical information. On average, participants correctly identified $84 \%(S E=2.4)$ of the faces. Corrected mean RTs for these familiar faces were calculated as in Experiment 1 and are presented, along with the mean percentage of errors, in Tables 1 and 2.
The data were submitted to a three-way ANOVA, with presentation format (edited, complete) as a between-subjects variable, and study status (studied, unstudied) and sex-of-face (male, female) as a within-subject variable. The main effects of study status achieved significance, with $46 \mathrm{~ms}$ faster processing of studied than of unstudied faces, $F_{1}(1,34)=13, M S E=5,986 ; F_{2}(1$, $118)=22.3, M S E=7,661$. For the other main effects, all $F s<1$. Of the two-way and three-way interactions, only the two-way interaction between study status and presentation format was significant, $F_{1}(1,34)=4.49, M S E=5,986 ; F_{2}(1,118)=3.97$, $M S E=7,661$, portraying the 55-ms larger repetition priming effect in the edited-face condition relative to the complete-face condition. For the accuracy data, the only effect that was found significant was sex-of-face, $F(1,34)=4.13, M S E=19$. All other main effects and interactions were not significant, discounting a speed-accuracy trade-off.

The results of Experiment 4 demonstrate that sex judgments can produce repetition priming for familiar faces. In conformity with the truncated-processing hypothesis, the effects were found only for faces for which the internal features could not be ignored. For complete faces, significant repetition priming was not found. Apparently, the reactivation of FRUs requires processing of the internal facial features. Even if the test task required processing sex rather than identity, repetition priming could emerge as long as the internal features were processed.

\section{Are Sex Judgments Affected by the Familiarity of Faces? An Analysis Across Experiments 1, 2, \& 4}

This experiment enables an additional comparison to help determine the validity of the parallel-route hypothesis. A. W. Ellis et al. (1990) found that sex judgments were not made faster for familiar than for unfamiliar faces. They interpreted the absence of a familiarity effect as suggesting that sex judgments were not made at the same locus at which faces were recognized as familiar (i.e., the FRUs), because a common locus should have produced slower judgments of sex for unfamiliar faces, for which prior representations were not stored, than for familiar faces.

Although the absence of a familiarity effect is interesting, it is not clear how stable it is. For example, Bruce (1986) found a familiarity effect, with faster sex judgments to familiar faces than to unfamiliar faces. The finding of her study is especially important, because identical stimuli were used in the familiar and the unfamiliar conditions, with the familiarity of the faces being determined by different subject populations. Although Bruce (1986) suggested that two photos may have carried the effect, still, these two photos constituted $25 \%$ of the stimuli in the critical condition and should not be dismissed based on post hoc criteria that are performance dependent.

Another failure to replicate the A. W. Ellis et al. (1990) result may be found in Bruce et al. (1987). Although sex judgments were not significantly faster for familiar faces, the familiarity effect was found in the accuracy data (that were not submitted to statistical analysis), with sex judgments to familiar faces being more accurate than to unfamiliar faces. Finally, H. D. Ellis, Ellis, and Hoise (1993) also failed to replicate the absence of the familiarity effect.

As described in the Method section, study format (edited, complete) was completely confounded in the present experiment with test format (edited, complete). Therefore, to further investigate the 
affects of familiarity on sex judgments, we compared the results of this experiment with the edited-face study condition of Experiment 1 (i.e., study, edited; test, edited) and the complete-face study condition of Experiment 2 (i.e., study, complete; test, complete). Because the affects of familiarity on sex judgments should not depend on memory, we performed the comparison only for unstudied faces for which memory representations had not been stored.

We found that RTs to familiar faces were $100 \mathrm{~ms}$ faster than to unfamiliar faces, $F_{1}(1,98)=13.6, M S E=22,956 ; F_{2}(1,334)=$ $175, M S E=26,061$, suggesting that sex judgments may be processed in the same route as the processing of identity.

Although this familiarity effect concurs with our general conclusion that sex and identity are processed by the same routes, the interpretation of the familiarity effect is unclear. Because a different stimulus set was used for familiar and unfamiliar faces, the different processing times may reflect differences in the ease with which participants made sex judgments to photos from the two stimulus sets. Therefore, although the familiarity effect is consistent with our prediction, its interpretation remains equivocal.

\section{Experiment 5}

In Experiment 4, repetition priming was observed for familiar faces, using the sex-judgment task, thereby endorsing the notion that FRUs are able to mediate sex judgments. Proponents of the parallel-route hypothesis may still argue, however, that upon making the initial intelligence judgments, pictorial codes were stored in routes that run parallel to the FRUs. If the sex of the faces was registered in such codes, then access to the codes, upon subsequent presentation of the same face for sex judgments, may help processing be done more quickly and more accurately.

Accordingly, an alternate locus to the FRUs could account for our effects. The locus of repetition priming may be the reactivation of pictorial codes, which represent particular pictures of faces. These codes are distinct from the abstract, view-independent structural records that are represented in FRUs (Bruce \& Young, 1986). Although each specific picture of a particular individual's face may create a unique pictorial code, it should create the same structural record. Therefore, to argue that structural records (represented in FRUs), not pictorial codes (stored in the parallel route), mediated the priming effects, it must be demonstrated that the priming effects can survive transformations of important pictorial dimensions such as viewpoint (Bruce, 1982), expression (Bruce, 1982), or lighting (e.g., Hill \& Bruce, 1996).

To conclude that an abstract record mediated repetition priming performance, different pixels must be activated at study and test. In Experiment 5, the faces that were presented at study and test were different exemplars of the same face, taken at different times, under different lighting conditions, and from different viewpoints. If repetition priming would still emerge, then abstract representations can be implicated as mediating our priming effects.

\section{Method}

Because repetition priming did not occur for complete faces in Experiment 4, only edited faces were presented to the 18 undergraduate participants. For 58 of the familiar faces used in Experiment 4, new exemplars were found, either from newspapers or from Internet sites (see Figure 2).
The new exemplars depicted photos taken at different times, under different lighting conditions, and from a viewpoint changed from that of the original exemplars. Two of the Experiment 4 faces, for which new exemplars could not be found, were replaced with new faces, for which pairs of distinct exemplars were found, resulting in 60 (original) Set 1 and 60 (new) Set 2 stimuli.

The Set 2 exemplars were digitized, standardized, and edited as in the preceding experiments (see Figure 2). Set 1 exemplars were presented at study for the intelligence-rating task. Set 2 exemplars were presented during test for sex judgments. In all other respects, the method conformed to that of Experiment 4 .

\section{Results and Discussion}

As in Experiment 4, means were calculated only for faces for which participants could provide some biographical information (89\%, SE $=2.3$ ). Corrected mean RTs were calculated for these faces as in Experiment 1 and are presented, along with the mean percentage of errors, in Tables 1 and 2.

The results of this experiment were compared with performance in the edited-face condition in Experiment 4, where the same exemplars were used at study and test. We submitted the data to an ANOVA, with exemplar compatibility (same exemplars as in Experiment 4, different exemplars as in Experiment 5) as a between-subjects variable and study status and sex-of-face as within-subject variables.

RTs were $19 \mathrm{~ms}$ faster to male faces than to female faces $F(1$, $34)=4.8, M S E=3,715$. This pattern replicated that found in Experiments 1 and 2 for unfamiliar faces. More important, across the two exemplar-compatibility conditions, responses were $49 \mathrm{~ms}$ faster for studied than for unstudied faces, $F_{1}(1,34)=18$, $M S E=4,739 ; F_{2}(1,118)=18, M S E=7,715$.

Although repetition priming was observed across the two exemplar-compatibility conditions, the Study Status $\times$ ExemplarCompatibility interaction, $F_{1}(1,34)=4.56, M S E=4,739 ; F_{2}(1$, 118) $=5.8, M S E=771,525$, established that the 25-ms effect in the different-exemplar condition was significantly smaller than the 74-ms effect in the same-exemplar condition. Critically, even when examined alone, repetition priming in the different-exemplar condition was significant, $F_{1}(1,17)=7.12, M S E=779 ; F_{2}(1$, $59)=2.33, M S E=6,681, p<.07$, one-tailed.

The accuracy data revealed no significant main effects or interactions, with the exception of the sex-of-face effect, which showed $1.85 \%$ less accurate responses for female faces than for male faces, $F_{1}(1,34)=6.18, M S E=20$.

This experiment established that the repetition priming effect that was observed in Experiment 4 survived transformation across exemplars that differed in pictorial dimensions considered important for facial processing. Still, the repetition priming effects in this experiment were considerably smaller in magnitude than those observed in Experiment 4, where identical exemplars were presented at study and test. This finding is typical of studies that present different study and test exemplars. For example, Warren and Morton (1982) showed reduced tachistoscopic exposure thresholds for the identification of studied, as compared with unstudied, objects. Facilitation of object recognition was greatest if the same picture was shown at test, and was lower if a different exemplar from the same category was shown. An identical pattern of results has been reported for familiar faces, using a familiarityjudgment task (Bruce \& Valentine, 1985; A. W. Ellis, Young, 
Flude, \& Hay, 1987). Warren and Morton (1982; see also A. W. Ellis et al,, 1987) suggested that priming between different views arises only from the abstract (structural record, or) pictogen. The advantage shown by repetition of the same view should be attributed, therefore, to an additional visual memory component (i.e., pictorial code) that can retain information about particular pictorial instances (but see Biederman \& Cooper, 1991, for an alternative interpretation).

The finding that repetition priming for faces can survive transformations across different photos, taken at different times, under different lighting conditions, and from different viewpoints, suggests that an abstract form of representation mediates repetition effects for faces in our sex-judgment task. Furthermore, like repetition priming for objects, when the same exemplars are used at study and test, an additional memory component, the pictorial code, works to facilitate performance yet further. At bottom, our findings suggests that sex judgments can extract facial information that is available in abstract form within the FRUs.

Although we have demonstrated that repetition priming for familiar faces endured transformations across exemplars, it remains an open question whether repetition priming to unfamiliar face can also endure similar transformations. Unfortunately, such a finding may prove difficult to establish because of possible floor effects that may result from the small effect size for unfamiliar faces. Either way, for the present purpose it has been established that sex judgments to familiar faces are mediated by abstract FRUs and, by extension, that this task should also involve FRUs that mediate repetition priming for unfamiliar faces (see also the Discussion section of Experiment 1).

\section{General Discussion}

In this article, repetition priming occurred for both unfamiliar and familiar faces in a sex-judgment task for hair-deleted faces but not for hair-included faces. This novel finding is important because it challenges the validity of the parallel-route hypothesis (e.g., Bruce \& Young, 1986) that claims that FRUs are not involved in sex judgments.

We argue that our findings are best interpreted by the truncatedprocessing hypothesis (e.g., Roediger \& McDermott, 1993), which suggests that abstract perceptual records (Kirsner \& Dunn, 1985) cannot be reactivated unless the repeated stimulus is processed in it's entirety, as a perceptual whole. Without perceptual records to support them, repetition priming effects cannot be found. As applied in this article, this hypothesis suggests that the involvement of FRUs requires processing the entire face, specifically the internal facial features. However, when asked to make sex judgments to hair-included stimuli (Experiment 2), participants adopted a hairstyle heuristic, ignoring the internal facial features.

In the pilot experiment, we found that the information that is available in the hairstyle was sufficient for making accurate sex judgments to unfamiliar faces. This suggests that the application of this heuristic is not unfeasible. More direct support for the idea that the heuristic was applied was found when repetition priming to unfamiliar faces appeared for hair-deleted faces (Experiment 1). Evidently, upon making sex judgments, participants did not rely on the information available in the hairstyle, but rather attended to the internal facial features, and FRUs could then be reactivated.
A further prediction from the truncated-processing hypothesis was that sex judgments, presented during study of complete faces, should not facilitate subsequent performance. The rationale behind this prediction was that in making sex judgments to complete faces, participants would ignore the internal facial features. The ensuing processing of faces would, therefore, be diminished and a perceptual record would not be created. This prediction was confirmed in Experiment 3.

The final two experiments generalized our findings to familiar faces. In Experiment 4, repetition priming was observed for hairdeleted faces, as it had been for unfamiliar faces. In Experiment 5 , repetition priming still emerged, despite the shift in exemplars from study to test. Because the two sets of exemplars were taken at different times, under different lighting conditions, and at different viewpoints, the persistence of repetition priming demonstrates that abstract records, which are represented in FRUs, support sex judgments.

One concern that may be raised about our findings is that the task that was used to uncover them is restricted to the investigation of "distorted" faces, for which the hair was deleted. As such, their ecological validly may be undermined. Our reply to this concern is that other researchers have also concealed hair (e.g., Bruce et al., 1993) or transformed (e.g., Bruce, 1986) the hair of facial stimuli. Indeed, the question of what constitutes good stimuli is pretheoretic. If anything, we contend that our "hairless" stimuli are ideal for studying first-order face recognition processes that are not influenced by local heuristics. Our stimuli contain all of the internal facial features, their relative organization, and the facial gestalt. We believe that our stimuli elicit only facial processing.

\section{Size of Repetition Priming Effects Across Different Tasks and Stimuli}

The time scale in which sex judgments were made and the subsequent effects that emerged in the studies reported in this article were different from those found in "standard" facerecognition research. In comparison with the familiarity-judgment task (e.g., Bruce \& Valentine, 1985), in which repetition priming is quite large (at least $100 \mathrm{~ms}$ in size), the repetition priming effects in this article were of only intermediate magnitude for familiar faces (i.e., $74 \mathrm{~ms}$ ) and were very small for unfamiliar faces (i.e., 32 $\mathrm{ms}$ ). It could be argued, therefore, that the mechanisms that mediate primed sex judgments are quite different from those reported elsewhere.

Our rebuttal to this argument is based on the notion that the magnitude of repetition priming is influenced by overall processing times of the task on hand, with slower tasks (e.g., familiarity) yielding larger repetition priming effects. Studies that examined familiarity judgments and sex judgments for the same stimulus set, found that judgments were considerably slower for familiarity than for sex (e.g., Bruce et al., 1987; A. W. Ellis et al., 1990). Because of the slower processing that is involved in making familiarity judgments, repetition can exert a relatively larger benefit to performance on this task.

In support of this rebuttal, A. W. Ellis et al. (1990, Experiment 4) found that when judgments regarding familiarity were performed quickly, by the introduction of brief presentations and a response deadline, the repetition priming effects that ensued were smaller (i.e., $79 \mathrm{~ms}$, almost identical to the $74 \mathrm{~ms}$ in Experiment 4). 
This can explain why the sex-judgment task, for which responses are quick to begin with, is expected to produce repetition priming effects of only an intermediate magnitude.

Note that A. W. Ellis et al. (1990, Experiment 4) were not able to demonstrate priming using the sex-judgment task, even when overall response times were equated with response times for the familiarity-judgment task. Thus, when speed on the two tasks was equated, repetition priming emerged only on familiarity judgments. This finding is important in that it demonstrates that it is not sufficient to simply reduce processing times for repetition priming to emerge on the sex-judgment task. As shown in this article, for repetition priming to emerge in this task, attention must be directed to the internal facial features by presenting edited faces.

But what of the small, $30-\mathrm{ms}$ repetition priming effect for unfamiliar faces? Does the small magnitude of this effect suggest that a different mechanism mediated this effect? We believe that the data may actually be most compatible with the notion that abstract FRUs mediated performance for both classes of stimuli. For, had these effects been mediated by nonabstract pictorial codes, then a single pictorial code should have been laid down for both familiar and unfamiliar faces, yielding priming effects of equal magnitude for the two stimuli classes.

The considerably smaller effects that were found for unfamiliar faces implies, according to our suggestion, that abstract FRUs mediated both repetition priming effects. The difference in the magnitude of these effects can then be interpreted as stemming from the different nature of the FRUs that mediate performance on the two classes of stimuli, with processing being advantageous for the established FRUs in which a strong abstract perceptual record was stored, over weaker FRUs, which contain only weak abstract perceptual records.

We suggest, therefore, that because the FRUs, corresponding to unfamiliar faces, were created by only a single study exposure, their absolute contribution to subsequent performance was small. Their relative contribution, however, considering that they had been created only through a single study episode, was remarkably large. Therefore, the different magnitude of repetition priming effects that was found for familiar and unfamiliar faces does not undermine our interpretation that the repetition priming effects were mediated by abstract FRUs.

\section{Implications for the Dual-Route Hypothesis}

Face-recognition models have, without exception, defended the parallel-route hypothesis when claiming that separate routes exist for extracting the identity of perceived faces and extracting visual information other than identity. The evidence in this article casts doubts on this hypothesis. In our demonstrations, faces were processed more quickly when they were presented a second time than upon initial presentation. The effect was item specific, in that facilitation was not observed for some general ability to categorize faces but rather was specific to faces that had been previously presented in the study phase. Consequently, repetition priming was based on the ability to extract facial information regarding individual faces per se, and this effect emerged on a task that required sex judgments. We infer from these findings that information regarding sex is processed by the same system that processes identity and advance the notion of only a single system, one that processes face identity as well as other facial characteristics.
According to our suggestion, the evidence that supports the dual-route hypothesis must be reexamined. First, the neuropsychological double dissociation between face identification and visual information has been observed anly for expression and face identity. With regard to sex and face identity, only a single dissociation exists. Thus, although there are reports of patients impaired on identification but intact on sex categorization (e.g., Tranel et al., 1988), there are no reports of patients impaired on sex categorization but intact on identification (for a similar conclusion, see Bruce, 1986). This single dissociation could be attributed to task difficulty, with the more difficult task (identification) breaking down before the easier task (sex classification) under neurological damage.

Second, results that indicate activation of different brain areas when participants categorize faces according to apparent sex than when they recognize familiar and new faces (Andreasen et al., 1996) may be due to participants moving from the analysis of internal facial features to the analysis of only superficial features, which ensues from applying the hair heuristic to aid performance. If information from hair and overall head shape can be used to perform accurate sex categorization (i.e., pilot experiment), then participants would search different areas of displayed faces and perform different types of calculations from those involved in face identification.

Finally, evidence for the parallel-route hypothesis obtained from normal participants turns out to be problematic. The first type of evidence comes from the inability to demonstrate repetition priming using sex-judgment tasks. The generality of this finding has been called into question by the present set of experiments. The second type of evidence comes from the finding that RTs for sex judgments were unaffected by whether the judged faces were familiar (A. W. Ellis et al., 1990). However, other studies have found that sex judgments could be speeded by face familiarity (Bruce, 1986; H. D. Ellis et al., 1993; see also the accuracy data in Bruce et al., 1987, Experiment 2). Moreover, upon comparing performance in Experiment 4 (familiar faces) with performance in Experiments 1 and 2 (unfamiliar faces), we found that participants made significantly faster sex judgments to familiar faces than to unfamiliar faces.

The present study focused on sex judgments. We were able to make the repetition priming effects appear and disappear, by adding or deleting hair from the facial stimuli. At the present time, it is not clear whether other types of manipulations would, likewise, enable repetition priming, as in, for example, an expressionjudgment task (e.g., "Is the face happy?") or a speech-sound task (e.g., "Is the face uttering 'oo' or 'ee'?"). Experimental participants are very astute at finding heuristics that can help them solve seemingly difficult tasks with minimal effort. It does not seem unlikely, therefore, that future research will uncover local heuristics that can mediate performance on such tasks (also see discussion of Experiment 3).

Equally probable, however, is the idea that expression and identity are not processed by the same system. Information regarding sex is always invariable within a single individual (well, almost always). In contrast, information regarding emotion or speech sound is considerably variable within a particular individual. It is, therefore, not unlikely that sex is represented with other invariant features (i.e., features of identity), whereas other information, regarding visual facial characteristics, is not. 
Accordingly, identity may be processed by the FRU system, whereas analysis of, for example, expressions may be processed by a parallel visual route. The neurological double dissociation that exists between expression (but not sex) and identity suggests that expression and identity are, in fact, processed by different systems. Hopefully, future research will determine whether identity and sex are processed by one system, whereas expressions and other visual facial characteristics are processed by yet another system.

\section{FRUs as the Locus of Repetition Priming: Resolving Apparent Discrepancies Between Models of Implicit Memory and Face-Recognition Models}

According to the memory systems account, domain-specific perceptual representation systems (PRS) are modified by the first encounter with a stimulus, and this change leaves a mnemonic signature-the perceptual record-that facilitates subsequent performance (e.g., Moscovitch, Goshen-Gottstein, \& Vriezen, 1993; Tulving \& Schacter, 1990). For example, it has been suggested that repetition priming for written words is mediated by the visual word-form system (Peterson, Fox, Posner, Mintun, \& Raichle, 1989; Warrington \& Shallice, 1980) for objects by the structural representation system (Riddoch \& Humphreys, 1987) and for spoken words by the auditory word-form system (e.g., Schacter \& Church, 1992).

Early face-recognition models were in complete conformity with the implicit memory literature when they proposed that, like repetition priming for other classes of stimuli, repetition priming for faces was also produced by reactivation of the representations that are stored within their recognition systems, that is, stored within the FRUs (Bruce \& Young, 1986; Hay \& Young, 1982). This suggestion went together with the idea that the familiarity of faces could be assessed directly from the level of activation in the FRUs and that these units, therefore, could be the locus of subsequent facilitation of behavior. Indeed, this suggestion is still advocated by some current models (e.g., Moscovitch, Winocur, \& Behrmann, 1997) in which the recognition system is labeled as the face module so as to avoid the theoretical baggage that the term $F R U$ carries with it. Note, that if reactivation of FRUs forms the basis of repetition priming, then there is no a priori reason to limit the type of task that can lead to such reactivation to, say, tasks of identity.

Later formulations of face-recognition models, however, proposed that familiarity of faces should be assessed at the modality independent person identification nodes (PINs), where information regarding the person, rather than the face, was represented. Information from many sources (e.g., name, voice, face) feeds into the PINs. Thus, "it would be more parsimonious for these various inputs to feed into a central pool of units at which decision of familiarity is made" (Burton et al., 1990, p. 365). With this departure from earlier models, the locus of repetition priming was redefined. Repetition priming was now construed as deriving from a later stage of processing, specifically from the strengthening of connections between FRUs and PINs, rather than from the changes within the FRUs (see also Burton, Bruce, \& Hancock, 1999; Burton, Kelly, \& Bruce, 1998; Young \& Burton, 1999).

The stated motivation for designating the PINs as the locus of familiarity judgments was to achieve parsimony regarding the locus of familiarity judgment with other input sources. ${ }^{3}$ Unfortu- nately, the parsimony that was gained by proposing a common locus for all judgments of familiarity was achieved at the price of dissension with the well-established notion that the locus of repetition priming is within the recognition systems that process incoming information. Indeed, face-recognition models had originally been designed to resemble models of reading, including the suggestion that specialized recognition units, FRUs, process structural facial information in the same way that another type of recognition unit, logogens, process structural (or lexical) information regarding word form (e.g., Morton, 1969, 1979; but see Wheeldon \& Monsell, 1992). The similar design of both models had been made in the name of parsimony (Bruce \& Young, 1986; Hay \& Young, 1982), so that, for example, both models could account for repetition priming via changes in activation thresholds within their respective recognition units. Not by coincidence, this original notion was virtually indistinguishable from current accounts of repetition priming, with perceptual records replacing the theoretically loaded logogens. The increase in parsimony within the face-recognition literature, therefore, sacrificed the built-in parsimony between models of face recognition and other cognitive models.

More important, the notion that repetition priming was mediated by the strengthening of the connections between FRUs and PINs may have carried within it hidden constraints. If repetition priming was the product of activation between units that represent a face (FRUs) and units that represent a person (PINs), then these effects would not be predicted to emerge for unfamiliar faces, for which connections between FRUs and the (nonexistent) PINs do not exist. Thus, as long as a face belonged to an unknown person, information regarding the person could not be stored in the PINs, and repetition could, therefore, not affect performance (see Burton, 1994, for a similar prediction).

By reallocating the locus of repetition priming effects, the generality of the later models became restricted to familiar faces that are processed with tasks regarding identity, with additional models required to describe the perception of unfamiliar faces. Such models are still absent, and only recently, has interest in memory for unfamiliar faces been rekindled (e.g., Bruce, Burton, \& Crow, 1992).

Our findings, which establish repetition priming for unfamiliar faces, may provide cause for a return to the original Bruce and Young (1986) model (Hay \& Young, 1982). This model can accommodate repetition priming to unfamiliar faces by changes that occur within FRUs. Thus, repetition priming for unfamiliar faces, like that of familiar faces, would be interpreted within the same theoretical framework, as stemming from the same locus and mediated via the same mechanism.

\footnotetext{
${ }^{3}$ The idea that FRUs were not the locus of repetition priming effects was first introduced in an article that described an interactive activation model for face recognition (Burton et al., 1990). The model was designed so that the input to the model would be the level of activation of the FRUs, with this activation passing along to PINs and to semantic units. Because the model accepted activation to the FRUs as its input, the locus of repetition priming had to be reassigned to a deeper level of processing. Note, however, that had front-end feature pools been added to the model (e.g. Burton, 1994) with the model accepting as input activation to the features, rather than to the FRUs, then the model might have been able to account for repetition priming just as easily through changes in the FRUs.
} 
For this model to work, however, one further assumption must be made. In Experiment 1, we found repetition priming to unfamiliar faces after single-study exposures. It must be assumed, therefore, that like repetition priming in other stimulus domains (see Roediger \& McDermott, 1993), single exposures are sufficient for the creation of FRUs. This assumption is quite easy to defend, in that we are at times able to recognize a person that we have encountered only once. Although quite intuitive, this assumption is at odds with a recent simulation model that suggests that multiple study presentation are necessary to create FRUs (Burton, 1994). Either way, we contend that Experiment 1 provides the most relevant data, in providing clear evidence of repetition priming after single-study exposures for stimuli with no preexperimental FRUs.

Once this assumption has been validated, then a single model can account for repetition priming for both unfamiliar and familiar faces. In this model, repetition priming is mediated by the reactivation of FRUs, which are able to make judgments about identity, sex, and perhaps even expressions and other visual facial information (see discussion above). Moreover, if repetition priming for both classes of faces is located in the same FRUs, then the revisions that the model would have to undergo to describe the processes that are involved when an unfamiliar face becomes familiar may turn out to be not too complicated. If a goal of science is to formulate parsimonious accounts of data, then a backward step to the original model, as our data suggest, may turn out to be a forward step after all.

\section{References}

Alhoff, R. R., \& Cohen, N. J. (1999). Eye-movement-based memory effect: A reprocessing effect in face perception. Journal of Experimental Psychology: Learning. Memory, and Cognition, 25, 997-1010.

Andreasen, N. C., O'Leary, D. S., Arndt, S., Cizadlo, T., Hurtig, R., Rezai, K., Watkins, G. L., Ponto, L. B., \& Hichwa, R. D. (1996). Neural substrates of facial recognition. Journal of Neuropsychiatry and Clinical Neurosciences, 8, 139-146.

Beg, I., \& Snider, A. (1987). The generation effect: Evidence for generalized inhibition. Journal of Experimental Psychology: Learning, Memory, and Cognition, 13, 553-563.

Begleiter, H., Porjesz, B., \& Wang, W. (1994). Event-related brain potentials differentiate priming and recognition to familiar and unfamiliar faces. Electroencephalography and Clinical Neurophysiology, 94, 4149.

Bentin, S., \& McCarthy, G. (1994). The effects of immediate stimulus repetition on reaction time and event-related potentials in tasks of different complexity. Joumal of Experimental Psychology: Leaming, Memory, and Cognition, 20, 130-149.

Bentin, S., \& Moscovitch, M. (1988). The time course of repetition effects for words and unfamiliar faces. Journal of Experimental Psychology: General, 117, 148-160.

Biederman, I., \& Cooper, E. E. (1991). Priming contour-deleted images: Evidence for intermediate representation in visual object recognition. Cognitive Psychology, 23, 393-419.

Bower, G. H., \& Karlin, M. B. (1974). Depth of processing pictures of faces and recognition memory. Journal of Experimental Psychology, 103, 751-757.

Bowers, J. S. (1994). Does implicit memory extend to legal and illegal nonwords? Journal of Experimental Psychology: Learning. Memory. and Cognition, 20, 534-549.

Bruce, V. (1982). Changing faces: Visual and non-visual coding processes in face recognition. British Journal of Psychology, 73, 105-116.
Bruce, V. (1986). Influences of familiarity on the processing of faces. Perception, 15, 387-397.

Bruce, V. (1988). Recognizing faces. Hillsdale, NJ: Erlbaum.

Bruce, V., Burton, A. M., Carson, D., Hanna, E., \& Mason, O. (1994). Repetition priming of face recognition. In C. Umilta \& M. Moscovitch (Eds.), Attention \& performance XV: Conscious and nonconscious processes in cognition (pp. 179-201). Cambridge, MA: MIT/Bradford Press.

Bruce, V., Burton, A. M., \& Crow, I. (1992). Modeling face recognition. Philosophical Transactions of the Royal Society of London, B 335 , 121-128.

Bruce, V., Burton, A. M., Hanna, E., Healy, P., Mason, O., Coombes, A., Fright, R., \& Linney, A. (1993). Sex discrimination: How do we tell the difference between male and female faces? Perception, 22, 131-152.

Bruce, V., Ellis, H., Gibling, F., \& Young, A. (1987). Parallel processing of the sex and familiarity of faces. Canadian Journal of Psychology, 41, 510-520.

Bruce, V., Healey, P., Burton, A. M., Doyle, E., Coombes, A., \& Linney, A. (1991). Recognizing facial surfaces. Perception, 20, 775-769.

Bruce, V., \& Langton, S. (1994). The use of pigmentation and shading information in recognizing the sex and identities of faces. Perception, 23, 803-822.

Bruce, V., \& Valentine, T. (1985). Identity priming in the recognition of familiar faces. British Journal of Psychology. 76, 363-383.

Bruce, V., \& Young, A. (1986). Understanding face recognition. British Journal of Psychology, 77, 305-327.

Burton, A. M. (1994). Learning new faces in an interactive activation and competition model. Visual Cognition, 1, 313-348.

Burton, A. M., Bruce, V., \& Dench, N. (1993). What's the difference between men and women? Evidence from facial measurement. Perception, 22, 153-176.

Burton, A. M., Bruce, V., \& Hancock, P. J. B. (1999). From pixels to people: A model of familiar face recognition. Cognitive Science, 23 , $1-31$.

Burton, A. M., Bruce, V., \& Johnston, R. A. (1990). Understanding face recognition with an interactive activation model. British Journal of Psychology, 81, 361-380.

Burton, A. M., Kelly, S. W., \& Bruce, V. (1998). Cross domain repetition priming in person recognition. Quarterly Journal of Experimental Psychology: Human Experimental Psychology, 51A, 515-529.

Campbell, R., Brooks, B., De Haan, E. H. F., \& Roberts, T. (1996). Dissociating face processing skills: Decisions about lip-read speech, expression, and identity. Quarterly Journal of Experimental Psychology, 49A, 295-314.

Campbell, R., \& De Hann, E. H. F. (1998). Repetition priming for face speech images: Speech-reading primes face identification. British Journal of Psychology, 89, 309-323.

Carlesimo, G. M., \& Caltagirone, C. (1995). Components in the visual processing of known and unknown faces. Journal of Clinical and Experimental Neuropsychology, 17, 691-705.

Challis, B. H., \& Brodbeck, D. R. (1992). Level of processing affects priming in word fragment completion. Joumal of Experimentul Psychology: Learning, Memory, and Cognition, 18, 595-607.

Clark, H. (1973). Language-as-a-fixed-effect-fallacy: A critique of language statistics in psychological research. Journal of Verbal Learning and Verbal Behavior, 12, 335-359.

Dorfman, J. (1994). Sublexical components in implicit memory for novel words. Journal of Experimental Psychology: Learning, Memory, and Cognition, 20, 1108-1125.

Ellis, A. W., Flude, B. M., Young, A. W., \& Burton, A. M. (1996). Two loci of repetition priming in the recognition of familiar faces. Journal of Experimental Psychology: Learning, Memory, and Cognition, 22, 295308.

Ellis, A. W., Young, A. W., \& Flude, B. M. (1990). Repetition priming and 
face processing: Priming occurs within the system that responds to the identity of a face. Quarterly Journal of Experimental Psychology, 42A, 495-512.

Ellis, A. W., Young, A. W., Flude, B. M., \& Hay, D. C. (1987). Repetition priming of face recognition. Quarterly Joumal of Experimental Psychology, 39A, 193-210.

Ellis, H. D., Ellis, D., \& Hosie, J. (1993). Priming effects in children's face recognition. British Journal of Psychology, 84, 101-111.

Goshen-Gottstein, Y., \& Kempinsky, H. (in press). Probing memory with conceptual cues at multiple retention intervals: A comparison of forgetting rates on implicit and explicit tests. Psychonomic Bulletin \& Review.

Goshen-Gottstein, Y., \& Moscovitch, M. (1995a). Repetition priming effects for newly formed associations are perceptually based: Evidence from shallow encoding and format specificity. Journal of Experimental Psychology: Learning, Memory, and Cognition, 21, 1249-1262.

Goshen-Gottstein, Y., \& Moscovitch, M. (1995b). Repetition priming for newly formed and preexisting associations: Perceptual and conceptual influences. Journal of Experimental Psychology: Learning, Memory, and Cognition, 21, 1229-1248.

Graf, P., \& Schacter, D. L. (1985). Implicit and explicit memory for new associations in normal and amnesic patients. Journal of Experimental Psychology: Learning, Memory, and Cognition, 11, 501-518.

Greene, R. L. (1989). Immediate serial recall of mixed modality lists. Joumal of Experimental Psychology: Learning, Memory, and Cognition. 15, 266-274.

Gregg, V. (1976). Word frequency recognition and recall. In J. Brown (Ed.), Recall and recognition. New York: Wiley.

Hay, D. C., \& Young, A. W. (1982). The human face. In A. W. Ellis (Ed.), Normality and pathology in cognitive functions. London: Academic Press.

Hayman, C. A. G., \& Jacoby, L. L. (1989). Specific word transfer as a measure of processing in the word-superiority paradigm. Memory \& Cognition, 17, 125-133

Hill, H., \& Bruce, V. (1996). Effects of lighting on the perception of facial surfaces. Journal of Experimental Psychology: Human Perception and Performance, 22, 986-1004.

Humphreys, G. W., Donnelly, N., \& Riddoch, M. J. (1993). Expression is computed separately from facial identity, and it is computed separately for moving and static faces: Neuropsychological evidence. Neuropsychologia, 31, 173-181.

Jacoby, L. L., \& Dallas, M. (1981). On the relationship between autobiographical memory and perceptual learning. Joumal of Experimental Psychology: General, 110, 306-340.

Kirsner, K., \& Dunn, D. (1985). The perceptual record: A common factor in repetition priming and attribute priming. In M. I. Posner \& O. S. M. Marin (Eds.), Attention and performance XI (pp. 547-566). Hillsdale, NJ: Erlbaum.

Kurucz, J., \& Feldmar, G. (1979). Prosopo-affective agnosia as a symptom of cerebral organic disease. Journal of the American Geriatrics Society, 27, 225-230.

Malone, D. R., Morris, H. M., Kay, M. C., \& Levine, H. S. (1982). Prosopagnosia: A double dissociation between the recognition of familiar and unfamiliar faces. Journal of Neurology, Neurosurgery and Psychiatry, 45, 489-501.

Morton, J. (1969). Interaction of information in word recognition. Psychological Review, 76, 165-178.

Morton, J. (1979). Facilitation in word recognition: Experiments causing change in the logogen model. In P. A. Kolers, M. Wrolstad, \& H. Bouma (Eds.), Processing of visible language. New York: Plenum.

Moscovitch, M., Goshen-Gottstein, Y., \& Vriezen, E. (1993). Memory without conscious recollection: A tutorial review from a neuropsychological perspective. In C. Umilta \& M. Moscovitch (Eds.), Attention and perfornance $X V$ : Conscious and nonconscious processes in cognition (pp. 619-660). Cambridge, MA: MIT/Bradford Press.
Moscovitch, M., \& Umilta, C. (1990). Modularity and neuropsychology: Implications for the organization of attention and memory in normal and brain darnaged people. In M. E. Schwartz (Ed.), Modular processes in dementia (pp. 1-59). Cambridge, MA: MIT/Bradford.

Moscovitch, M., \& Umilta, C. (1991). Conscious and nonconscious aspects of memory: A neuropsychological framework of modules and central systems. In R. G. Lister \& H. J. Weingartner (Eds.), Perspectives in cognitive neuroscience (pp. 229-266). Oxford, England: Oxford University Press.

Moscovitch, M., Winocur, G., \& Behrmann, M. (1997). What is special about face recognition? Nineteen experiments on a person with visual object agnosia and dyslexia but normal face recognition. Journal of Cognitive Neuroscience, 9, 555-604.

O'Toole, A. J., Vetter, T., Troje, N. F., \& Bulthoff, H. H. (1997). Sex classification is better with three-dimensional head structures than with image intensity information. Perception, 26, 75-84.

Paller, K. A., Mayes, A. R., Thompson, K. M., Young, A. W., Roberts, J., \& Meudell, P. R. (1992). Priming of face matching in amnesia. Brain and Cognition, 18, 46-59.

Patterson, K. E., \& Baddeley, A. D. (1977). When face recognition fails. Journal of Experimental Psychology: Human Learning and Memory, 3 406-417.

Peterson, S. E., Fox, P. T., Posner, M. I., Mintun, M. A., \& Raichle, M. E. (1989). Positron emission topographic studies of the processing of single words. Journal of Cognitive Neuroscience, 1, 153-170.

Pollatsek, A., \& Well, A. D. (1995). On the use of counterbalanced designs in cognitive research: A suggestion for a better and more powerful analysis. Joumal of Experimental Psychology: Learning, Memory, and Cognition, 21, 785-794.

Riddoch, M. J., \& Humphreys, G. W. (1987). Visual object processing in optic aphasia: A case of semantic access agnosia. Cognitive Neuropsychology, 4, 131-186.

Reingold, E. M., \& Goshen-Gottstein, Y. (1996). Separating consciously controlled and automatic influences in memory for new associations. Joumal of Experimental Psychology: Learning, Memory, and Cognition, 22, 397-406.

Rizzo, M., Hurtig, R., \& Damasio, A. R. (1987). The role of scanpaths in facial recognition and learning. Annals of Neurology, 22, 41-45.

Roberts, A. D., \& Bruce, V. (1989). Repetition priming of faces in a serial choice reaction time task. British Journal of Psychology, 80, 201-211.

Roediger, H. L., \& McDermott, K. B. (1993). Implicit memory in normal human subjects. In H. Spinnler \& F. Boller (Eds.) \& F. Boller \& J. Grafman (Vol. Eds.), Handbook of neuropsychology (Vol. 8, pp. 63131). Amsterdam: Elsevier.

Schacter, D. L. (1987). Implicit memory: History and current status. Journal of Experimental Psychology: Learning. Memory, and Cognition, 13, 501-518.

Schacter, D. L. (1990). Perceptual representation systems and implicit memory: Toward a resolution of the multiple system debate. In A Diamond (Ed.), Development and neural bases of higher cognition (pp. 543-571). New York: New-York Academy of Sciences.

Schacter, D. L., \& Church, B. (1992). Auditory priming: Implicit and explicit memory for words and voices. Joumal of Experimental Psychology: Learning, Memory, and Cognition, 18, 915-930.

Schacter, D. L., Cooper, L. A., \& Delaney, S. M. (1990). Implicit memory for unfamiliar objects depends on access to structural descriptions. Journal of Experimental Psychology: General, 119, 5-24.

Schacter, D. L., Cooper, L. A., Delaney, S. M., Peterson, M. A., \& Tharan, M. (1991). Implicit memory for possible and impossible objects: Constraints on the construction of structural descriptions. Journal of Experimental Psychology: Learning, Memory, and Cognition, 17, 3-19.

Schacter, D. L., \& Tulving, E. (1994). Memory systems 1994. Cambridge, MA: MIT Press.

Schweich, M., \& Bruyer, R. (1993). Heterogeneity in the cognitive man- 
ifestations of prosopagnosia: The study of a group of single cases. Cognitive Neuropsychology, 10, 529-547.

Schweinberger, S. R., Pfutze, E. M., \& Sommer, W. (1995). Repetition priming and associative priming of face recognition: Evidence from event-related potentials. Journal of Experimental Psychology: Learning, Memory, and Cognition, 21, 722-736.

Takahashi, M., Kawamura, M., Hirayama, K., Shiota, J., \& Isono, O. (1995). Prosopagnosia: A clinical and anatomical study of four patients. Cortex, 31, 317-329.

Thapar, A., \& Greene, R. L. (1994). Effects of level of processing on implicit and explicit tasks. Journal of Experimental Psychology: Learning, Memory, and Cognition, 20, 671-679.

Tranel, D., Damasio, A. R., \& Damasio, H. (1988). Intact recognition of facial expression, sex, and age in patients with impaired recognition of face identity. Neurology, 28, 690-696.

Tulving, E., \& Schacter, D. L. (1990). Priming and human memory systems. Science, $247,301-305$.

Tulving, E., \& Thomson, D. M. (1973). Encoding specificity and retrieval processes in episodic memory. Psychological Review, 80, 352-373.

Uhl, F., Lang, W., Spieth, F., \& Deecke, L. (1990). Negative cortical potentials when classifying familiar and unfamiliar faces. Cortex, 26, 157-161.

Warren, C., \& Morton, J. (1982). The effects of priming on picture recognition. British Journal of Psychology. 73, 117-129.

Warrington, E. K., \& James, M. (1967). An experimental investigation of facial recognition in patients with unilateral cerebral lesions. Cortex, 3. 317-326.
Warrington, E. K., \& Shallice, T. (1980). Word-form dyslexia. Brain, 102. 43-63.

Wentura, D. (2000). Dissociative affective and associative priming effects in the lexical decision task: Yes versus No responses to word targets reveal evaluative judgment tendencies. Journal of Experimental Psychology: Learning, Memory, and Cognition, 26, 456-469.

Wheeldon, L. R., \& Monsell, S. (1992). The locus of repetition priming of spoken word production. Quarterly Journal of Experimental Psychology: Human Experimental Psychology, 44A, 723-761.

Winograd, E. (1976). Recognition memory for faces following nine different judgments. Bulletin of the Psychonomic Society, 8, 419-421.

Young, A. W., \& Burton, A. M. (1999). Simulating face recognition: Implications for modeling cognition. Cognitive Neuropsychology, 16, $1-48$.

Young, A. W., McWeeny, K. H., Hay, D. C., \& Ellis, A. W. (1986). Matching familiar and unfamiliar faces on identity and expression. Psychological Research, 48, 63-68.

Young, A. W., Newcombe, F., De Haan, E. H. F., Small, M., \& Hay, D. C. (1993). Face perception after brain injury: Selective impairments affecting identity and expression. Brain, 116, 941-959.

Received August 10, 1998

Revision received March 28, 2000

Accepted March 28, 2000 